\title{
El perfil del cazador/a social en la comunidad autónoma de Extremadura
}

\author{
Public access hunter profiles in the Spanish region of Extremadura
}

\author{
Luz María Martín Delgado ${ }^{1^{*}}$ (iD \\ Juan Ignacio Rengifo-Gallego ${ }^{2}$ (ID \\ José-Manuel Sánchez-Martín ${ }^{3}$ (iD
}

\section{Resumen}

La actividad cinegética presenta un notable arraigo social, cultural, histórico, territorial y económico en la comunidad autónoma de Extremadura. En esta región destaca la existencia de dos modelos de caza: la social y la económica. Desde la asunción de competencias en materia de caza en 1983 por parte del gobierno autonómico ha tratado de darse la misma importancia territorial a ambos modelos cinegéticos. Este escenario ha desembocado en que, en la actualidad, los terrenos acotados dedicados a la práctica social abarquen aproximadamente la mitad de la superficie cinegética bajo la consideración de coto. La presencia de la caza en Extremadura ha llevado a la creación de un buen número de trabajos científicos que se decantan por esta temática. A pesar de ello, una escasa parte de estos trabajos abordan la caza social. De esta manera, la mayor parte de ellos se inclinan por otras líneas de investigación (económica, ambiental, etc.). Ante esta carencia de estudios el siguiente trabajo se expone como novedoso al analizar una de las partes más importantes de la caza social, sus practicantes, determinando su perfil, así como la situación de esta modalidad cinegética. Para conseguir mencionados objetivos se ha empleado como fuente de información principal una encuesta difundida entre cazadores extremeños a través de la asistencia a diferentes eventos cinegéticos (jornadas, ferias, etc.). Estos datos han sido tratados, posteriormente, mediante técnicas estadísticas que han permitido obtener una información relevante.

Palabras clave: Actividad cinegética; Extremadura; caza social; cazador; perfil.

\begin{abstract}
Hunting is socially, culturally, historically, territorially, and economically deeply rooted in the Spanish region of Extremadura. The existence of two models of hunting are highlighted: public access and economic. Since the assumption by the regional government of regulatory powers over hunting, the government has tried to give the same territorial importance to both models of hunting. Therefore, at present, approximately half of the hunting grounds are public access and open to all hunters. The presence of hunting in Extremadura has led to the creation of many scientific works that focus on this subject. However, only a small number of these works deal with public access hunting. Thus, most works are inclined towards other lines of research (economic, environmental, etc.). For this reason, the following work is presented as novel when analysing some of the most important parts of public access hunting, its practitioners, their profile, as well as the situation of this type of hunting. For this purpose,

1 Universidad de Extremadura, España. luzmariamd@unex.es. Autora para correspondencia

2 Universidad de Extremadura, España. irengifo@unex.es

3 Universidad de Extremadura, España. jmsanche@unex.es


a survey of hunters in Extremadura has been used as the main source of information and the survey was issued at various hunting events (conferences, fairs, etc.). These data have been subsequently processed using statistical techniques that have allowed the relevant information to be obtained.

Keywords: Hunting; Extremadura; public access hunting; hunter; profile.

\section{Introducción}

\subsection{Antecedentes}

La tradición cinegética de Extremadura es dilatada y rica. Su pasado histórico ha sido analizado de forma detallada (Terrón, M., 1971, 1975, 1987, 1992 y 2002; Terrón, A., 1981) tomando como fuente de estudio los textos que conforman la literatura clásica venatoria, algunos de ellos escritos por autores extremeños (Zapata, 1979; Mateos, 1979; Varona, 1976 y Covarsí, 1998). A estos libros, considerados clásicos, pueden añadirse otras fuentes directas e indirectas, a través de las cuales se puede corroborar la práctica ininterrumpida de la actividad cinegética. Gracias a estos textos se ha ido configurando un corpus bibliográfico que contiene información válida para el conocimiento de la historia de la veterinaria, historia natural, geografía cinegética, toponimia o descripción de paisajes (Fradejas, 2017). En el caso de Extremadura, el Libro de la Montería del siglo XIV constituye un punto de partida para construir un relato histórico de la práctica cinegética y la distribución de especies en la región, en su calidad de excepcional obra de geografía cinegética (López, 1991). Por profundizar en lo que este texto contiene en su libro tercero, hay que aludir a la localización de alrededor de 200 montes donde la presencia de osos y jabalíes era habitual. Con la ayuda de las obras mencionadas, así como de otras fuentes, se puede hacer un análisis diacrónico de la distribución de especies de caza en siglos posteriores, si bien en desigual medida por el número de lugares incluidos. Entre las fuentes más clarificadoras se encuentran las Relaciones topográficas de Felipe II (Campos, 2003), el Interrogatorio de la Real Audiencia de Cáceres del año 1790 (Rodríguez y Barrientos, 1993, 1994, 1995 y 1996) y los diccionarios Geográficos de Tomás López de finales del siglo XVIII (Barrientos, 1991) y el de Pascual Madoz en el siglo XIX (Madoz, 1953).

Con la ayuda de estos y otros documentos se puede constatar que la caza en Extremadura ha ido cambiando a lo largo de los siglos, al igual que lo ha hecho en otros lugares del mundo. Estos cambios han afectado a los medios utilizados y, principalmente, a los fines, como consecuencia del paulatino abandono de su tradicional carácter utilitario, cuyo principal objetivo era proporcionar sustento alimenticio o proteger las cosechas, hasta alcanzar su actual concepción como práctica esencialmente ociosa y recreativa. No obstante, el papel funcional de la caza permanece vigente en la actualidad para evitar daños a cultivos y ganados, evitar accidentes y mantener el equilibrio natural en determinados espacios, cuestión que genera un amplio debate, por ejemplo, entre asociaciones de agricultores y ganaderos y grupos ecologistas y animalistas. En este sentido, la administración se ha dotado de herramientas legales, como la de la declaración de "emergencia cinegética", cuya finalidad es la de evitar riesgos a las especies o sus hábitats, la conservación o protección del medio natural, la seguridad pública o la transmisión de zoonosis (Artículo 130 del Decreto 34/2016, de 15 de marzo).

\subsection{Contexto actual}

No cabe duda de que en el marco de la sociedad postindustrial que predomina actualmente se ha generalizado el carácter lúdico-recreativo de la caza (Alvarado, 1991a), en consonancia con la mayor disposición de rentas, acceso a la motorización, mercantilización, nuevo marco normativo y disposición de más horas de tiempo libre que se reflejan en una nueva cultura del ocio. Una consecuencia de esta nueva situación se aprecia en el incremento del número de licencias expedidas a lo largo del siglo XX, denominada boom cinegético en algún periodo determinado (años 60 y 70), cuestión que ha sido puesta de manifiesto en diversos trabajos realizados por diferentes geógrafos (Mulero, 1991a; López, 1981, 1993; Martínez, 2009). Extremadura no permaneció al margen de este proceso, y registró un crecimiento sostenido del número de licencias expedidas (Instituto Nacional para la Conservación de la Naturaleza, 1970-1980), especialmente tras la aprobación y entrada en vigor de la Ley de Caza de 1970, si bien en los últimos años muestra una tendencia inversa (Gallardo et al., 2018). Sin embargo, las estadísticas globales no revelan detalles sobre aspectos cualitativos de los cazadores, careciendo de información sobre aspectos claves como su nivel socio-económico, movilidad, intensidad en su práctica, motivaciones específicas, 
etc. Esta carencia de conocimiento sigue siendo una realidad a día de hoy que solo puede ser subsanada a través de la investigación con la ayuda de técnicas como la encuesta o entrevista.

En síntesis, se puede afirmar que Extremadura tiene una larga tradición cinegética, característica que no es de extrañar si se tienen en cuenta factores sociales, económicos e históricos, así como sus indudables valores paisajísticos y ambientales, atributos que han caracterizado a este territorio como un escenario idóneo para la proliferación de multitud de especies de caza (Terrón, M., 1975).

Bajo estas circunstancias, la realidad actual de la caza en Extremadura viene definida por un contexto en el que conviven dos modelos de aprovechamiento cinegético: comercial y social. Si nos centramos en el segundo de los modelos, que es el objeto de este trabajo de investigación, los orígenes de la caza social habría que relacionarlos con el cambio de la consideración de las especies de caza como un recurso económico, en vez de la tradicional consideración de bien de libre aprovechamiento (res nullius), circunstancia que contribuyó a incrementar el número de terrenos cinegéticos cerrados y, al mismo tiempo, redujo la superficie libre para cazar (Alvarado, 1991a). Por ello, ante este escenario, el cazador más modesto vio reducida la superficie en la que practicar la actividad cinegética (Montero, 2019). Esta situación está claramente vinculada con el cambio de paradigma que se produjo tras la publicación de la Ley de 1970, que supuso la aparición de un mayor número de cotos privados como resultado del propósito principal de la norma que pasaba por incrementar la caza (Martínez, 2009).

La coexistencia de los dos modelos de aprovechamiento cinegético en Extremadura ha sido expuesta en trabajos que han tenido como espacio temporal de análisis el reciente periodo autonómico, comprendido entre la década de los años ochenta del siglo pasado y la actualidad (Alvarado, 1983, 1991b; Rengifo, 2012; Martín, Rengifo y Sánchez, 2019a, 2020), tras la pertinente descentralización de competencias del Estado en favor de las comunidades autónomas. Esta nueva etapa se inicia tras la asunción de las competencias en materia de caza en Extremadura en 1984, mediante el traspaso contemplado en el Real Decreto 1594/1984, de seis de febrero de 1984 y con los antecedentes del Estatuto de Autonomía aprobado en 1983 en la Asamblea de Extremadura. A partir de este momento, la comunidad autónoma fue desarrollando un extenso corpus normativo de carácter regional, cuya finalidad era la de regular esta actividad en su ámbito territorial, siendo uno de sus principios básicos garantizar el derecho a la caza, en régimen de igualdad, que tienen todos los ciudadanos, con independencia de condicionantes sociales o económicos (Junta de Extremadura, Ley 8/1990).

En este orden de ideas, dicha ley trató de otorgar un mayor protagonismo a los terrenos cinegéticos de aprovechamiento común (coloquialmente conocidos como terrenos libres) para que el cazador más modesto dispusiera de terrenos donde cazar (Junta de Extremadura, Ley 8/1990) al tiempo que introducía figuras de acotados, denominados deportivos, que podrían ser locales o no. Posteriormente, la normativa ha ido experimentando cambios sin abandonar nunca el planteamiento dual de caza comercial y caza social.

Como principio básico de este nuevo ordenamiento, se fija el doble reconocimiento de la caza como actividad social y económica. Distinción que pretende dar cobertura a esta actividad cuando va asociada a la cultura y al ocio, y que se organiza en Sociedades Locales, al tiempo que como actividad económica aporta alternativas y complemento al desarrollo y empleo rural (Junta de Extremadura, Ley 14/2010, Ley 12/2014, Ley 9/2019).

Como consecuencia de ello, la clasificación de terrenos cinegéticos (Figura 1), conforme a la normativa vigente, determina tipologías que se vinculan con ambos modelos: cotos sociales (prototipo de terreno destinado a la caza social, cuya presión impositiva es muy baja), Reservas y Cotos Regionales de Caza (en ellos el cazador tiene acceso a la práctica venatoria mediante el sorteo anual por parte de la Junta de Extremadura de una serie de permisos) y cotos privados (ejemplo de coto con finalidad lucrativa que recibe una presión impositiva mucho más elevada, cuestión que ha sido contestada en muchas ocasiones por gestores y empresas especializadas).

Bajo este contexto normativo, tanto el número de cotos sociales, como la superficie afectada por estos (Tabla 1) y la relación de Sociedades Locales de Cazadores han experimentado un importante crecimiento, al tiempo que ejercen un papel decisivo como baluartes defensivos del cazador con menor poder adquisitivo al poner a disposición de los mismos una serie de terrenos donde cazar (Mulero, 1991a). El mayor crecimiento de este tipo de agrupaciones de cazadores en Extremadura se produjo en la década de los ochenta (Martín, et al., 2019a) caracterizándose por su amplio reparto entre, prácticamente, la totalidad de los 388 municipios de Extremadura y agrupando a una buena parte de los cazadores residentes en esta comunidad. 


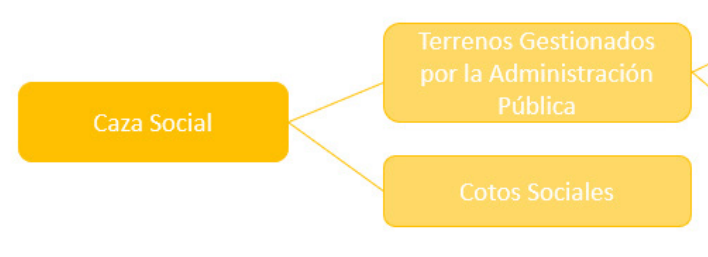

\section{Reservas Regionales de Caza}

Cotos Regionales de Caza

\section{Menor Extensivo}

\section{Menor Extensivo + Jabalí}

Menor + Intensivo
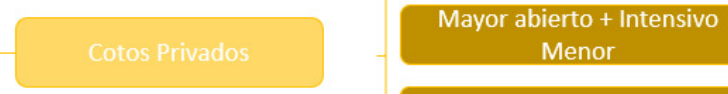

Menor

Mayor Abierto

Mayor Cerrado

Mayor Cerrado+ Intensivo Menor

Elaboración propia

Tabla 1. Distribución superficial de terrenos cinegéticos. Temporada (2016/2017)

\begin{tabular}{|l|c|c|c|c|c|c|}
\hline \multicolumn{1}{|c|}{ Tipo de terreno cinegético } & \multicolumn{2}{c|}{ Cáceres } & \multicolumn{2}{c|}{ Badajoz } & \multicolumn{2}{c|}{ Extremadura } \\
\hline & $\mathrm{Ha}$ & $\%$ & $\mathrm{ha}$ & $\%$ & $\mathrm{Ha}$ & $\%$ \\
\hline Coto Social & 788.607 & 48,98 & 927.121 & 50,02 & 1.715 .728 & 49,53 \\
\hline Privado Menor Extensivo & 169.164 & 10,51 & 445.264 & 24,02 & 614.428 & 17,73 \\
\hline Privado Menor más Jabalí & 160.519 & 9,97 & 175.537 & 9,47 & 336.056 & 9,70 \\
\hline Privado Menor Intensivo & 51.320 & 3,19 & 40.726 & 2,20 & 92.046 & 2,65 \\
\hline Privado Mayor Abierto & 316.144 & 19,64 & 187.735 & 10,13 & 503.879 & 14,54 \\
\hline Privado Mayor Abierto más Intensivo de Menor & 13.887 & 0,86 & 10.881 & 0,59 & 24.768 & 0,71 \\
\hline Privado Mayor Cerrado & 108.779 & 6,76 & 61.007 & 3,29 & 169.786 & 4,95 \\
\hline Privado Mayor Cerrado más Intensivo de Menor & 1.533 & 0,10 & 5.378 & 0,29 & 6.911 & 0,19 \\
\hline Total & 1.609 .953 & 100,00 & 1.853 .649 & 100,00 & 3.463 .602 & 100,00 \\
\hline
\end{tabular}

Fuente: Gallardo et al., 2018. Elaboración propia

La tabla anterior refleja que los cotos sociales alcanzan casi, la misma entidad porcentual (49,53\%) de la suma de todas las tipologías de cotos privados existentes (50,47\%). Por tanto, nos encontramos con el hecho de que el peso superficial de ambos modelos está equilibrado, si bien, no existe una correlación entre superficie y abundancia de caza, tal y como ha sido puesto de manifiesto en otros trabajos (Martín, et al., 2019a).

En esta breve radiografía sobre la caza en Extremadura hay que mencionar que es un sector económico que genera empleo y diversifica la economía rural por su repercusión en numerosos negocios de diverso tipo, tal y como ha sido acreditado a escala nacional en el reciente estudio de la Fundación Artemisan (Andueza et al., 2018). Por su parte, la Federación Extremeña de Caza en su último informe sobre la caza a nivel regional (Gallardo et al., 2018) realizó una estimación para la temporada 2017/2018 que cifró en 385 millones de euros la economía vinculada con la caza en Extremadura. 


\subsection{Marco teórico}

Teniendo en cuenta la repercusión social, económica, ambiental y territorial de la caza en Extremadura, parece lógico que esta actividad haya despertado el interés de los investigadores, de cara a la realización de diferentes tipos de estudios científicos. Como puede observarse en la Figura 2, la mayor producción científico-técnica tuvo lugar en la década de los ochenta, concretamente, destacó el número de trabajos del año 1987. Sin embargo, hay que advertir que esta situación se debió a la celebración del I Congreso Internacional de Caza en Extremadura (1987), acontecimiento que en aquella época tuvo una incuestionable repercusión, y de la que surgió un buen número de estudios de carácter más técnico. Por otro lado, con la entrada en vigor de la primera ley de caza autonómica (Junta de Extremadura, Ley 8/1990) se aceleró la publicación de trabajos que han seguido desarrollándose hasta la actualidad.

Figura 2. Evolución de los trabajos científicos sobre caza en Extremadura

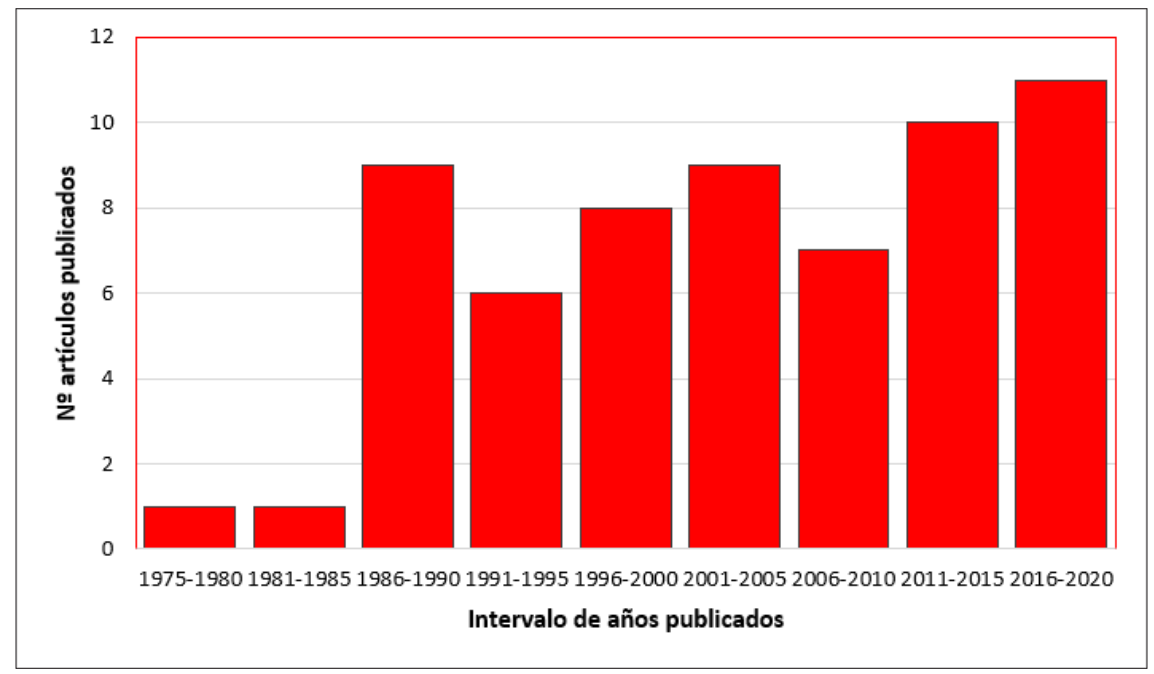

Fuente: datos recopilados de fuentes bibliográficas (Scopus, Web of Science, Google Scholar, Dialnet, Biblioteca Universidad de Extremadura). Elaboración propia

A continuación, con el interés de evaluar el peso que ha tenido la caza social en el marco de las contribuciones científicas, se ha procedido a realizar un análisis bibliométrico. El procedimiento seguido ha sido el siguiente:

- Consulta en bases de datos científicas (Dialnet, biblioteca de la Universidad de Extremadura, Web of Science, Scopus, Google Scholar) sobre los estudios que han abordado la caza en Extremadura. Para ello, se han utilizado como conceptos clave las palabras: caza y Extremadura

- Posteriormente, con la información extraída de dichos repositorios, se procedió a la construcción de una base de datos en la que estos trabajos se han organizado por año, autor y temática.

- Además, se ha contrastado la información elaborada en este estudio con la descrita por Barceló, Grimalt y Binimelis (2017), aunque cabe mencionar que este trabajo tan sólo recopila las investigaciones centradas desde una perspectiva geográfica. Por ello, el número de trabajos que menciona en la comunidad autónoma de Extremadura durante el período 1978-2015 se reduce a 15, mientras que esta investigación ha podido confirmar la existencia de 61 estudios que abordan la caza en esta comunidad desde distintas perspectivas.

Los trabajos encontrados han sido agrupados en bloques, con cierto grado de homogeneidad, para favorecer la comparabilidad:

En primer lugar, se ha elaborado un bloque general en el cual se integran aquellos trabajos que abordan multitud de aspectos vinculados con la caza (temática general de carácter trasversal) como puede ser su papel económico, contextualización de la caza en un momento determinado, connotaciones ambientales, etc. sin focalizarse en un tema de forma monográfica. Este tipo de estudios representan la mayor parte de las investigaciones (Terrón M., 1975, 1987, 2003; Viola, 1987; Alvarado, 1983; Bardají, 1987; Calvo, 1988; Ledesma, 1989; Aparicio y Vargas, 1991; Alvarado, Carranza y Beltrán, 1991; Fernández, 1992; Fuentes y Sánchez, 1992; Lázaro, 2004). 
Otro bloque de trabajos aborda cuestiones de tipo ambiental ligadas a la conservación de especies y terrenos cinegéticos (García, 1987; Morgado, 1998; Rocha e Hidalgo, 2000; Hidalgo y Rocha, 2001; Hidalgo y Rocha, 2005; Serrano y Martínez, 2005; Álvarez y Remedios, 2017)

En tercer lugar, hay que mencionar una gran parte de trabajos que se han centrado en el análisis de la actividad cinegética como sector económico, sobre todo, ligado al desarrollo del turismo cinegético (Bielsa, 1987; Alvarado, 1991a; Leco, 1997; Rubio y Pérez, 1998; EUROCAZA, 2001, 2002, 2003, 2004; Aparicio y Vargas, 2002; Álvarez, Coca y Hernández, 2007; Coca, 2015; Coca, Plaza, Del Río y Álvarez, 2015).

Finalmente se ha detectado un escaso número de estudios en las siguientes líneas temáticas: la caza como actividad físico-deportiva (Guzmán y Gamonales, 2012; Gamonales, Guzmán y Muñoz, 2016), sus implicaciones normativas (Castilla, 2000) y el análisis de la caza social (Martín, et al., 2019a).

Figura 3. Trabajos agrupados por líneas de investigación

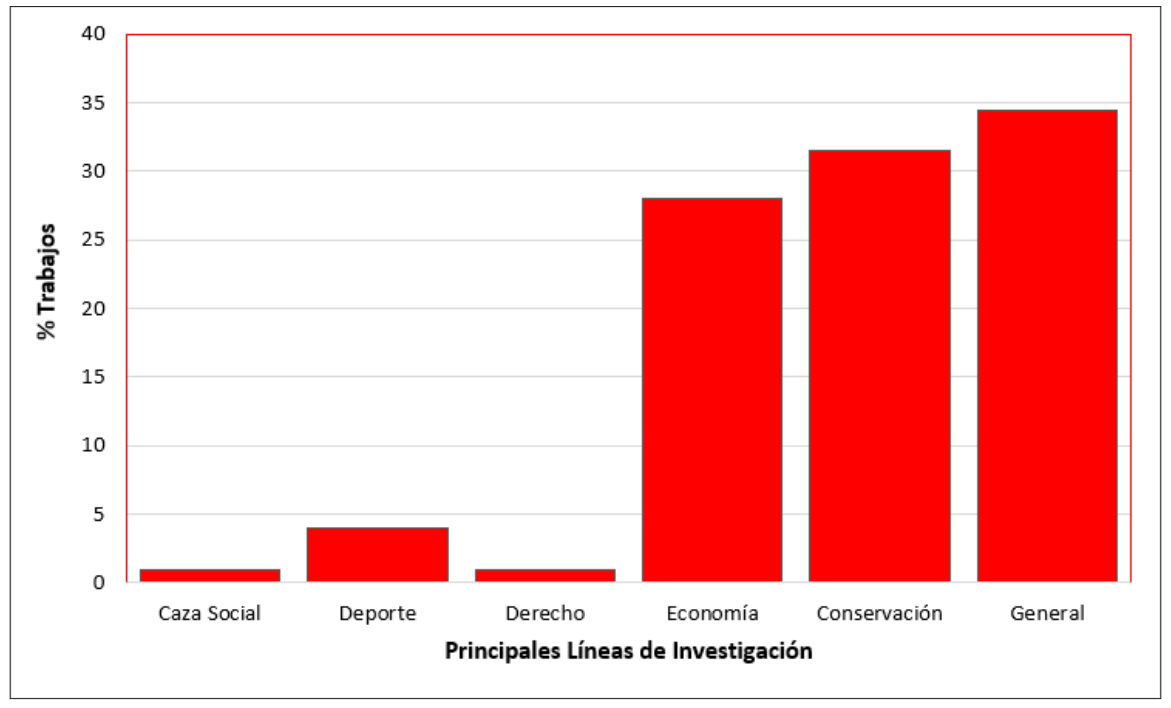

Fuente: datos recopilados de fuentes bibliográficas (Scopus, Web of Science, Google Scholar, Dialnet, Biblioteca Universidad de Extremadura). Elaboración propia

Tras este breve análisis bibliométrico puede apreciarse la carencia de estudios sobre el modelo de caza social en Extremadura, donde tan sólo existe un estudio que aborde de forma monográfica esta línea de investigación. A pesar de ello, cabe mencionar que, en algunos de los estudios que abordan desde una perspectiva global la actividad cinegética, se recogen diferentes menciones sobre este modelo de caza.

\subsection{Hipótesis y objetivo}

Ante la ausencia de trabajos de investigación en los que se haya hecho una caracterización del perfil del cazador social en Extremadura, con este artículo se pretende alcanzar el objetivo de generar un conocimiento que vaya orientado a cubrir este vacío y dar continuidad al ya mencionado trabajo de investigación de (Martín, et al., 2019a). En concreto, la caracterización que se acomete aborda cuestiones relacionadas con aspectos sociales, demográficos, económicos, movimientos y particularidades relacionadas con la práctica cinegética. Este objetivo se pretende alcanzar partiendo de una hipótesis inicial en la que se considera que estos cazadores juegan un rol muy importante tanto a nivel social y económico, razón por la que no se entiende el hecho de que hayan sido tradicionalmente ignorados en los estudios realizados sobre la actividad cinegética.

\section{Metodología}

\subsection{Marco geográfico}

La caza social tiene como referente los terrenos de caza que normativamente son denominados cotos sociales, y que aparecen definidos por la ley vigente (Junta de Extremadura, Ley 14/2010) de la siguiente forma: 
Son aquellos cotos de caza cuya titularidad corresponde a las Sociedades Locales de Cazadores inscritas en el registro al que se refiere el artículo 71 y en los que el aprovechamiento cinegético se realiza por los socios, sin ánimo de lucro.

Los acotados sociales han alcanzado una gran importancia superficial en esta comunidad autónoma, donde abarcan prácticamente la mitad del territorio acotado (Gallardo et al., 2018) tal y como se ha comentado anteriormente y puede observarse en la Figura 4. Uno de los aspectos más relevantes que se detecta en la cartografía es su amplia distribución territorial, detectándose casos en los que estos cotos ocupan la práctica totalidad de algunos términos municipales. En sentido contrario, hay algunas áreas del territorio de gran tradición cinegética como Sierra de San Pedro, Villuercas, Siberia, Área de influencia de Monfragüe o sierras centrales de Badajoz, en las que los cotos sociales tienen una presencia mucho más limitada.

Figura 4. Cotos Sociales en Extremadura

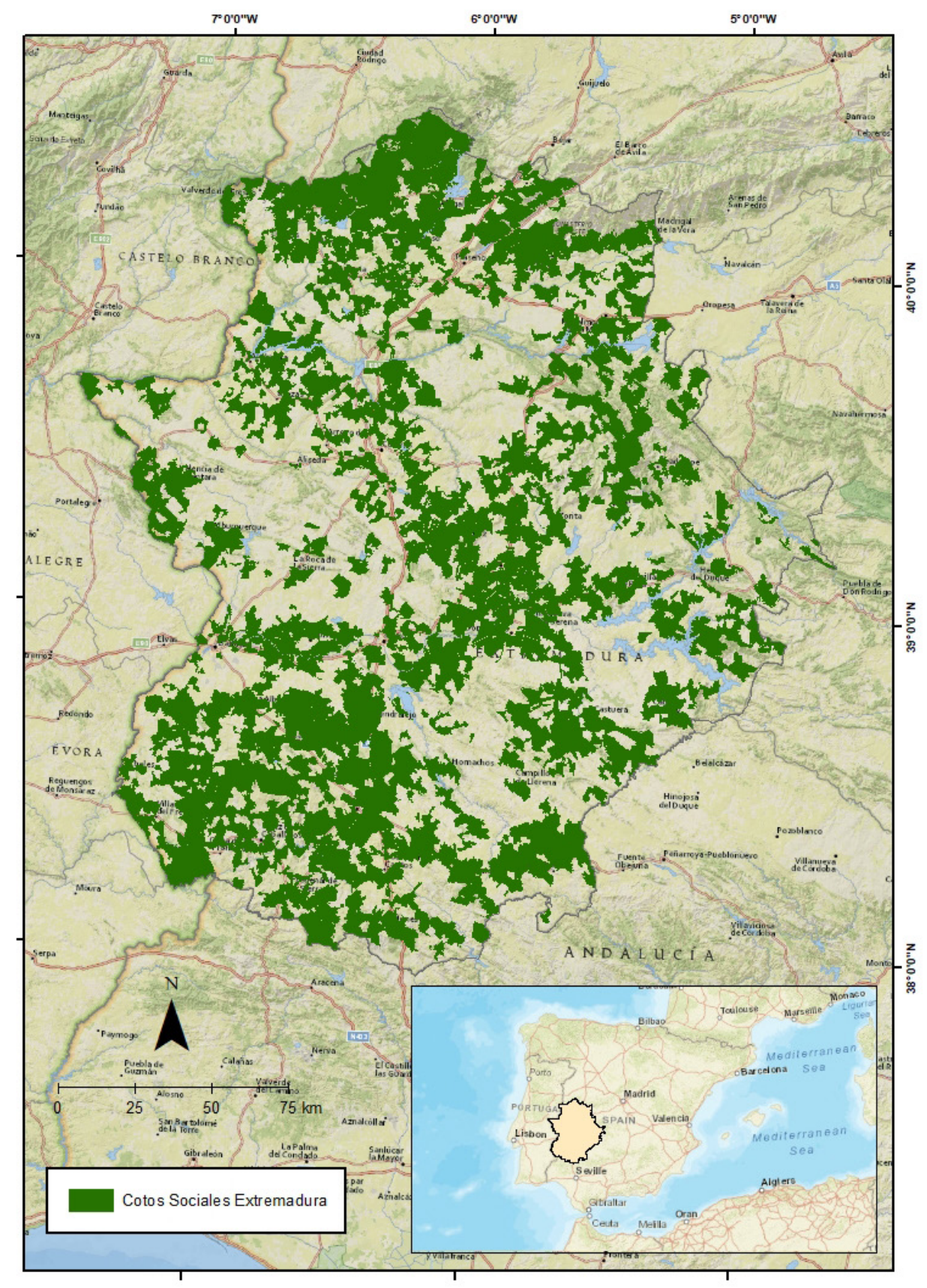

Fuente: Cartografía disponible en http://www.ideextremadura.com/Geoportal/ (2019). Elaboración propia. 
La definición que la legislación vigente realiza sobre coto social determina que este tipo de terrenos cinegéticos tiene que estar gestionado por las Sociedades Locales de Cazadores. Estas organizaciones presentan como uno de los principales objetivos poner a disposición del cazador más modesto una serie de terrenos donde cazar, ya que llevar a cabo esta práctica en cotos privados representa un desembolso superior. La carencia de otro tipo de terrenos en los que el cazador más modesto pueda practicar la actividad venatoria en esta comunidad autónoma, tras la supresión de los terrenos de aprovechamiento cinegético común en 2010, desembocó en la creciente importancia social de este tipo de terrenos. Asimismo, cabe mencionar que existen otros tipos de terrenos gestionados por la Administración Pública donde todo tipo de cazadores pueden desarrollar esta práctica, los Cotos y Reservas Regionales de Caza. Sin embargo, cazar en este tipo de terrenos cinegéticos es bastante complicado, ya que se sortea anualmente un reducido número de permisos que habilitan a su práctica, siendo un escaso porcentaje de cazadores los que resultan agraciados en él. En la actualidad, Extremadura cuenta con un total de 422 agrupaciones locales de cazadores federadas, según los datos aportados por la Federación Extremeña de Caza (2020). De ellas, 233 se ubican en la provincia de Cáceres y 189 en Badajoz. Estos datos acreditan la trascendencia que este tipo de agrupaciones ha alcanzado en la comunidad.

Las Sociedades Locales de Cazadores se caracterizan por el importante papel que juegan a nivel social, territorial y ambiental. Martín, et al. (2019a) han descrito sus principales características en las que determinan que estas organizaciones permiten el acceso a la caza a multitud de cazadores y desempeñan una indudable tarea en pro de la conservación del medio natural, a través de la puesta en marcha de diferentes medidas.

\subsection{Fuentes y metodología}

En este trabajo de investigación se ha recurrido al uso de las siguientes fuentes:

Fuentes primarias. La principal de estas fuentes procede del diseño y posterior distribución de un cuestionario dirigido, exclusivamente, a cazadores residentes en Extremadura. La encuesta, cuya estructura y tipo de preguntas aparece reflejada en la tabla 2, fue cumplimentada por 431 cazadores durante el período temporal que transcurrió entre el 15 de septiembre de 2018 y el 15 de septiembre de 2019, si bien, para este estudio solo se han tenido en cuenta las 270 que responden a la tipología de cazador que practica la actividad cinegética en el marco de las sociedades de cazadores (cazador social). Este amplio número de encuestas fue conseguido tras un trabajo de campo intenso que se secuenció de la siguiente forma (Figura 5):

- Diseño y distribución del cuestionario (en soporte papel y a través de soportes electrónicos) en distintos tipos de eventos: ferias monográficas de caza, competiciones de cazadores, jornadas de caza colectivas (monterías, ojeos etc.) y reuniones o jornadas vinculadas con el sector de la caza.

- Tras alcanzar el número de encuestas considerado óptimo, en el que la muestra de estudio fuese representativa, se procedió a crear una base de datos sobre la que se volcó la información.

- Finalmente, estos datos fueron tratados mediante técnicas estadísticas de carácter univariante y bivariante para la obtención de los resultados. Concretamente, se optó por el empleo de la distribución de frecuencias y, complementariamente, los coeficientes de correlación R de Pearson y Tau_b de Kendall. La elección de estos coeficientes de correlación radica en las características cualitativas ordinales de las variables de estudio. La aplicación de estos coeficientes permite establecer si existen o no relaciones entre las variables de estudio. De esta forma, cuando se obtiene un coeficiente 0 puede determinarse que no existe relación entre las variables de estudio; mientras que, si este resultado se sitúa entre los valores $0 \mathrm{y}+1$ existe una asociación positiva entre las variables, es decir, aumentan los valores de ambas variables al mismo tiempo. Por otro lado, si la aplicación de estos coeficientes da como resultado un valor situado entre 0 y - 1 , la asociación de las variables es negativa, de tal manera que al incrementarse el valor de una de ellas la otra disminuye.

Secundarias. La principal de estas fuentes procede de la difusión de un cuestionario entre los cazadores residentes en Extremadura durante el período temporal que va desde el 15 de septiembre de 2018 hasta el 15 de septiembre de 2019. Este formulario estaba formado por las preguntas que aparecen descritas en la Tabla 2. 
Tabla 2. Preguntas del cuestionario

\begin{tabular}{|c|c|}
\hline \multicolumn{2}{|c|}{ Bloque 1. Perfil sociodemográfico y económico } \\
\hline 1.1. Género & 1.2. Edad \\
\hline 1.3. Localidad de residencia & 1.4. Nivel de estudios \\
\hline 1.5. Situación laboral & 1.6. Ingresos mensuales \\
\hline \multicolumn{2}{|c|}{ Bloque 2. Tradición cinegética } \\
\hline 2.1. ¿A qué edad comenzó a cazar? & 2.2. ¿Ha sido la caza una actividad tradicional en su familia? \\
\hline $\begin{array}{l}\text { 2.3. ¿Cuántos miembros de su familia son cazadores? (padres, } \\
\text { hermanos/as, hijos/as) }\end{array}$ & $\begin{array}{l}\text { 2.4. Si tiene hijos, ¿practica el caza alguno de ellos o piensa } \\
\text { inculcarle esta actividad? }\end{array}$ \\
\hline \multicolumn{2}{|c|}{ Bloque 3. Viajes de caza } \\
\hline 3.1. Lugares en los que caza & 3.2. ¿Cuántos días viaja por temporada? \\
\hline \multicolumn{2}{|c|}{ 3.3. Indique el número de días que pernocta fuera de su lugar de residencia con motivo de la práctica cinegética } \\
\hline \multicolumn{2}{|c|}{ Bloque 4. Gastos durante la temporada de caza } \\
\hline 4.1. Gastos en desplazamientos & 4.2. Gastos relacionados con la adquisición de equipamiento \\
\hline \multicolumn{2}{|l|}{ 4.3. Otros gastos relacionados con la caza } \\
\hline \multicolumn{2}{|c|}{ Bloque 5. Modalidades de caza } \\
\hline 5.1. Modalidades de caza menor & 5.2. Modalidades de caza mayor \\
\hline 5.3. Frecuencia con la que caza en cotos sociales & 5.4. Frecuencia con la que caza en cotos privados \\
\hline $\begin{array}{l}\text { 5.5. ¿Podría cazar con la misma frecuencia si no existieran los } \\
\text { cotos sociales? }\end{array}$ & 5.6. ¿Está usted federado? \\
\hline
\end{tabular}

Elaboración propia

La encuesta es una técnica ampliamente utilizada en el análisis de algunos parámetros de la actividad cinegética, así como en la definición de perfiles de la demanda en diferentes sectores. En primer lugar, destaca el trabajo llevado a cabo por Barceló, Binimelis y Grimalt (2016) quienes emplean los cuestionarios para determinar los aspectos sociales y territoriales de los cazadores en Mallorca; Nogueras, Caridad y Gálvez (2017) utilizan esta técnica para delimitar el perfil del turista cinegético en Córdoba, junto a Martín, Rengifo y Sánchez (2019b), quienes se decantan por su análisis en la comunidad autónoma de Extremadura. Al mismo tiempo, pueden citarse numerosos estudios que abordan perfiles de la demanda en otros sectores (Barlés, 2012; Folgado y Hernández, 2014). Por ello, consideramos que la metodología utilizada en esta investigación es la adecuada para alcanzar el objetivo planteado en este artículo, máxime cuando la muestra es lo suficientemente representativa, tal y como se muestra en la Tabla 3.

Figura 5. Fases del proceso metodológico

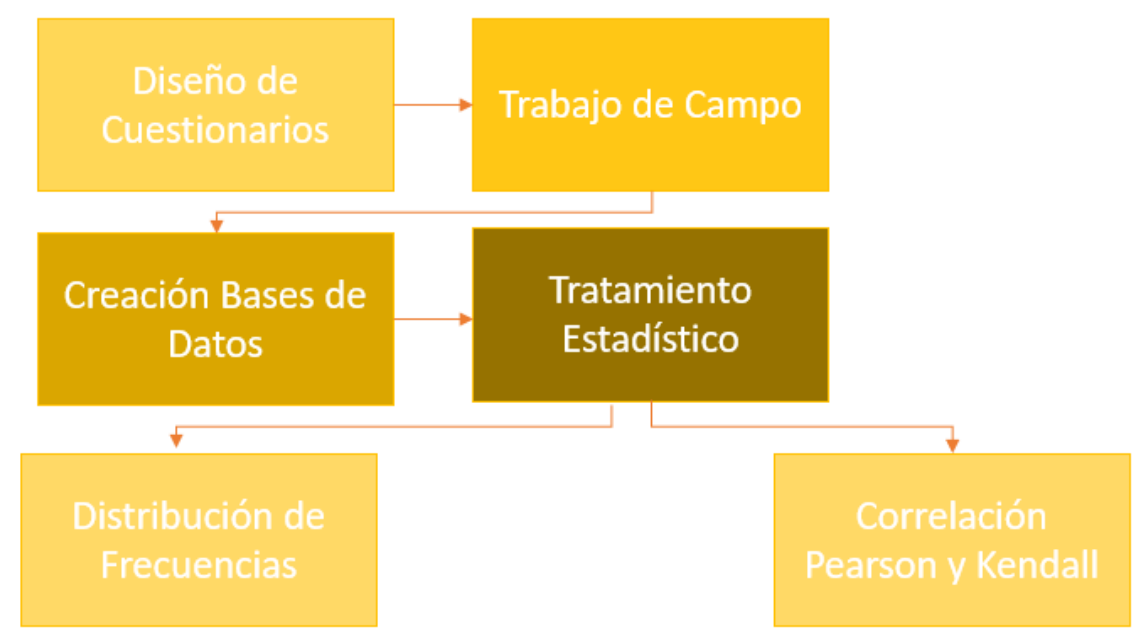

Elaboración propia 
El elevado número de encuestas recopiladas (270) ha permitido obtener una gran fiabilidad estadística de los datos (Tabla 3). El tamaño universal se ha fijado en el número de licencias expedidas en Extremadura durante el año 2019, ya que no se dispone del dato sobre el número de cazadores sociales residentes en esta comunidad. Estas cifras han llevado a que, para un nivel de confianza del 95\%, el error muestral se sitúe en el caso más desfavorable en el 5,9\% reduciéndose este dato en el escenario más favorable al 3,6\%.

Tabla 3. Ficha técnica

\begin{tabular}{|l|l|}
\hline Universo & 38.273 licencias expedidas en Extremadura (2019) \\
\hline Tamaño de la muestra & 270 cuestionarios cumplimentados \\
\hline Muestreo & Aleatorio simple \\
\hline Nivel de confianza & $95 \%$ \\
\hline Tipo de encuesta & Cuestionario en papel y en línea (Google Drive) \\
\hline Error muestral (pq=50; pq=90) & $5,9 \% ; 3,6 \%$ \\
\hline Fecha de realización & 15 de septiembre de 2018 hasta el 15 de septiembre de 2019 \\
\hline
\end{tabular}

Elaboración propia

Fuentes secundarias. Para la elaboración del marco teórico se ha hecho una revisión pormenorizada de la literatura existente sobre esta temática, desde la óptica geográfica y, complementariamente, desde otro tipo de enfoques. Asimismo, para contextualizar el fenómeno de la actividad cinegética a escala de Extremadura se ha recurrido a la consulta de las fuentes oficiales, cuyo proveedor es la Junta de Extremadura, teniendo en cuenta que las competencias en materia de caza están transferidas a las Comunidades Autónomas.

\section{Resultados}

\subsection{Perfil Sociodemográfico y Económico del Cazador Social en Extremadura}

El perfil sociodemográfico del cazador social residente en Extremadura se caracteriza, desde el punto de vista del género, por su masculinización. Este dato coincide con los resultados de otras investigaciones que abordan el perfil de la demanda en Extremadura (Martín, et al., 2019a; Gallardo et al., 2016) y en otros lugares (Nogueras et al., 2017). A pesar de ello, cabe precisar que la incorporación de la mujer se está incrementando en los últimos años (Martín, et al., 2019a). Con respecto a la edad de este cazador, los datos acreditan la presencia de un perfil maduro donde predominan los grupos de edad entre los 26 y 55 años, con una reducida representatividad del cazador joven menor de 26. Estas cifras evidencian uno de los problemas que, en la actualidad, afectan a la actividad cinegética al no estar asegurado el relevo generacional (Rengifo, 2012) donde, quizás, la reciente incorporación de la mujer puede ayudar a solventarlo. Por otro lado, destaca el bajo nivel formativo de la muestra de cazadores encuestados, al afirmar el 49,1\% que tienen una formación básica, frente al 21,9\% que expresan poseer estudios superiores. La situación laboral en la que se encuentran los encuestados refleja el predominio de los trabajadores por cuenta ajena $(42,8 \%)$ y los autónomos $(21,9 \%)$ frente a otras categorías como el estudiante, jubilado, funcionario o parado. Por otro lado, el escaso nivel formativo limita al cazador social, a priori, el acceso a escalas de trabajo con ingresos superiores, lo que conlleva el predominio de grupos de ingresos mensuales situados por debajo de los $1.000 €(25,3 \%)$ y entre 1.001 y $1.500 €(42,8 \%)$. De esta forma, aquellos cazadores con ingresos por encima de los $1.500 €$ representan una escasa parte de la muestra del estudio.

Tabla 4. Perfil Sociodemográfico y Económico

\begin{tabular}{|l|l|}
\hline Sexo & Frecuencia (\%) \\
\hline Mujer & 5,2 \\
\hline Hombre & 94,8 \\
\hline
\end{tabular}




\begin{tabular}{|l|l|}
\hline Grupos de edad & \\
\hline Menor de 18 años & 2,2 \\
\hline Entre 18 y 25 años & 13,4 \\
\hline Entre 26 y 40 años & 28,3 \\
\hline Entre 41 y 55 años & 33,5 \\
\hline Entre 56 y 65 años & 17,8 \\
\hline Más de 65 años & 4,8 \\
\hline Nivel de estudios & \\
\hline Bajo & 49,1 \\
\hline Medio & 29,0 \\
\hline Superior & 21,9 \\
\hline Situación laboral & \\
\hline Estudiante & 8,2 \\
\hline Parado & 6,7 \\
\hline Trabajador por cuenta ajena & 42,8 \\
\hline Funcionario & 9,7 \\
\hline Autónomo & 21,9 \\
\hline Jubilado & 10,0 \\
\hline Otros & 0,7 \\
\hline Nivel de ingresos mensuales (€) & \\
\hline Menos de 1000 & 25,3 \\
\hline Entre 1001 y 1500 & 42,8 \\
\hline Entre 1501 y 2000 & 13,0 \\
\hline Entre 2001 y 2500 & 5,9 \\
\hline Más de 2500 & 7,8 \\
\hline Ns/Nc & 5,2 \\
\hline & \\
\hline
\end{tabular}

Fuente: Datos procedentes de las encuestas. Elaboración propia

\subsection{La actividad cinegética, una práctica tradicional entre los cazadores sociales}

La caza es una actividad tradicional entre las familias de los cazadores sociales encuestados según afirma el 80,7\% de los casos, al ser practicada por un amplio número de familiares directos (padres, hijos, hermanos) que oscila entre los 2 y más de 10 . Al mismo tiempo, se observa como esta actividad ha sido inculcada de padres a hijos, iniciándose estos a edades muy tempranas, tras afirmar el 80,7\% de los casos que comenzaron a cazar con menos de 18 años. Esta tendencia parece continuar en la actualidad, aunque con una menor incidencia, ya que el $62,8 \%$ de los encuestados determina que alguno de sus hijos es cazador o, en el caso de menores, piensa imbuirles esta actividad tradicional.

Tabla 5. Tradición cinegética en el entorno familiar del cazador social

\begin{tabular}{|l|l|}
\hline \multicolumn{1}{|c|}{ Edad a la que comenzó a cazar } & Frecuencia (\%) \\
\hline Menos de 18 años & 80,7 \\
\hline Entre 18-25 años & 13,0 \\
\hline Entre 26-40 años & 4,1 \\
\hline Entre 41-50 años & 0,7 \\
\hline Entre 51-65 años & 0,7 \\
\hline Más de 65 años & 0,0 \\
\hline NS/NC & 0,8 \\
\hline
\end{tabular}




\begin{tabular}{|c|c|}
\hline ¿Ha sido la caza una actividad tradicional en su familia? & \\
\hline Sí & 80,7 \\
\hline No & 18,6 \\
\hline $\mathrm{NS} / \mathrm{NC}$ & 0,7 \\
\hline \multicolumn{2}{|l|}{ ¿Cuántos miembros de su familia son cazadores? } \\
\hline 0 & 0,4 \\
\hline $1-3$ & 74,3 \\
\hline $4-6$ & 16,0 \\
\hline $7-9$ & 2.2 \\
\hline 10 o más & 4,5 \\
\hline NS/NC & 2,6 \\
\hline \multicolumn{2}{|l|}{$\begin{array}{l}\text { Si tiene hijos, ¿practica el caza alguno de ellos o piensa inculcarles esta } \\
\text { tradición en el caso de que sean menores de edad? }\end{array}$} \\
\hline Sí & 62,8 \\
\hline No & 30,1 \\
\hline NS/NC & 7,1 \\
\hline
\end{tabular}

Fuente: Datos procedentes de las encuestas. Elaboración propia

\subsection{Viajes cinegéticos del cazador social}

Los cazadores realizan numerosos desplazamientos con motivo de la práctica venatoria durante toda la temporada de caza. La muestra de estudio del cazador social confirma este escenario, donde tan sólo el 15,6\% de ellos manifiesta no viajar para cazar fuera de su localidad de residencia. En función de la duración de estos desplazamientos existen dos tipos de viajeros cinegéticos: el excursionista $(33,8 \%)$ y el turista cinegético $(50,6 \%)$. La diferencia entre sendos perfiles radica en que el turista cinegético realiza movimientos que implican pernoctación en el destino con una duración del viaje superior a las 24 horas; mientras que, el excursionista, lleva a cabo movimientos de menos de 24 horas sin pernoctar en el destino.

Tabla 6. Incidencia del turismo cinegético en el cazador social

\begin{tabular}{|l|l|}
\hline \multicolumn{1}{|c|}{ Tipo de viajero } & Frecuencia (\%) \\
\hline Excursionista & 33,8 \\
\hline Turista & 50,6 \\
\hline No viaja & 15,6 \\
\hline \multicolumn{1}{|c|}{ Lugares en los que caza } & 15,6 \\
\hline Solo en el municipio en el que reside & 36,4 \\
\hline En el municipio en el que reside y en otros de su comunidad autónoma & 39,4 \\
\hline En su comunidad autónoma y en otras distintas & 8,6 \\
\hline En España y en otros países del extranjero & \\
\hline \multicolumn{1}{|c|}{ ¿Cuántos días viaja por temporada? } & 17,1 \\
\hline Entre 1 y 10 días & 15,2 \\
\hline Entre 11 y 20 días & 16,7 \\
\hline Entre 21 y 30 días & 46,5 \\
\hline Más de 30 días & 4,5 \\
\hline Ns/Nc & \\
\hline ¿Cuántos días pernocta fuera de su lugar de residencia por motivo de la actividad cinegética? & \\
\hline No pernocto & 48,0 \\
\hline Entre 1 y 5 días & 32,3 \\
\hline Entre 6 y 10 días & 9,3 \\
\hline Más de 10 días & 10,4 \\
\hline
\end{tabular}

Fuente: Datos procedentes de la encuesta. Elaboración propia. 
Estos desplazamientos se producen a tres escalas: autonómica, nacional e internacional. Los resultados obtenidos muestran la importancia de los movimientos autonómicos $(36,4 \%)$ y nacionales $(39,4 \%)$, con una reducida incidencia de los viajes fuera de las fronteras españolas $(8,6 \%)$. El número de días que el cazador social viaja durante la temporada de caza es elevado, ya que el $46,5 \%$ de la muestra de estudio afirma viajar más de 30 días. La orden de vedas (Consejería de Medio Ambiente y Rural, 2018) determina que el período generalista de caza se sitúa durante unos pocos meses invernales limitando los días hábiles para la práctica venatoria a fines de semana, festivos y puentes, ampliándose este período a los jueves en algunas modalidades específicas como la caza de liebre con galgos. Por ello, el elevado número de días que el cazador se desplaza con motivo de esta práctica determina la notable importancia de los movimientos cinegéticos, los cuales generan beneficios económicos.

Los desplazamientos realizados por el cazador social se caracterizan por una modesta incidencia en la pernoctación, donde el 48\% de aquellos que viajan para cazar manifiestan no pernoctar. Esta situación puede venir determinada por las diferencias que se dan entre el perfil del excursionista y el turista cinegético, ya que el primero de ellos dispone de un nivel de ingresos inferior al coincidir, en líneas generales, esta situación con el cazador social (Martín, et al., 2020). A pesar de ello, existe otro amplio porcentaje de la muestra que sí pernocta durante estos desplazamientos, mayoritariamente, entre 1 y 5 días por temporada $(32,3 \%)$.

\subsection{Modalidades de caza}

En Extremadura existen un total de 10 modalidades de caza menor y 6 de caza mayor (Junta de Extremadura, Ley 14/2010). Como puede apreciarse en la Tabla 7 , dentro de las modalidades dedicadas a la caza menor, la práctica al salto o en mano es la predilecta por el cazador social según afirman el 77,3\% de los encuestados. Esta modalidad consiste básicamente en la batida del terreno cinegético por el cazador que, puede ir acompañado o en solitario, así como con la ayuda o no de perros en busca de diferentes piezas de caza (Junta de Extremadura, Decreto 91/2012). Por otro lado, destacan las modalidades de puesto fijo $(59,1 \%)$ y cacería de zorros $(42,4 \%)$, aunque abarcando una menor parte de la muestra. El resto de las modalidades tienen una menor incidencia entre el cazador social: gancho de caza menor (32,3\%), perros en madriguera (27,9\%), la suelta para su abatimiento inmediato $(25,3 \%)$, ojeo $(17,8 \%)$, perdiz con reclamo $(12,6 \%)$, la caza con galgos $(8,6 \%)$ y la cetrería $(3,0 \%)$. Por otro lado, entre las modalidades de caza mayor destaca la incidencia de la montería practicada por más del $77 \%$ de los encuestados. Además, se encuentran las modalidades de aguardo o la espera $(55,8 \%)$ y la batida $(49,1 \%)$. El resto presentan una escasa incidencia entre la muestra de este estudio.

El coto de tipo social gestionado por sociedades locales de cazadores suele ser el lugar donde el cazador social practica su afición, tras manifestar el $45,7 \%$ de los encuestados que lo hace siempre en este tipo de terrenos y el $37,9 \%$ que lo hace habitualmente, frente a un escaso $4 \%$ que, a pesar de ser socio de una sociedad local, no acude nunca a este tipo de terrenos. Ante la importancia del coto social para este tipo de cazador, los cotos privados suelen frecuentarse con una menor asiduidad, al afirmar una escasa parte de los encuestados $(14,5 \%)$ que caza en este tipo de terrenos frente al resto que suele acudir a ellos con una menor regularidad. La relevancia del coto social para este tipo de cazador se debe a que, en la actualidad, apenas existen otros terrenos en los que cazar con esta facilidad, tras la supresión de los terrenos cinegéticos de aprovechamiento común en Extremadura, coloquialmente conocidos como terrenos libres, con la entrada en vigor de la Ley 14/2010, de 9 de noviembre, de caza en Extremadura.

Los cotos sociales tienen una notable importancia entre el cazador social, al afirmar más del $72 \%$ de la muestra que sin la existencia de estos no podría cazar con la misma frecuencia. Al mismo tiempo, un apreciable porcentaje de ellos $(27,5 \%)$ manifiesta que tendría la posibilidad de desarrollar esta práctica con la misma regularidad, aunque no existieran este tipo de acotados. Estos datos acreditan la importancia de la existencia de los acotados sociales para el cazador más modesto, ya que sin ellos no podrían cazar con la misma frecuencia.

Por último, hay que señalar que tras la publicación de la Ley 9/2019, de 5 de abril, de caza de Extremadura, y la Ley 18/2001, de 14 de diciembre sobre tasas y precios públicos de la Comunidad Autónoma de Extremadura, será obligatorio estar federado, dado que la nueva norma lo exige para cazar en los cotos sociales. Aunque en el momento de realización de esta encuesta no existía tal exigencia, los datos 
obtenidos acreditan la importancia de esta organización en la caza social de manera que el 81,8\% de los encuestados manifestaron pertenecer a ella.

Tabla 7. Modalidades de caza

\begin{tabular}{|c|c|}
\hline Modalidades de caza menor & Frecuencia (\%) \\
\hline Al salto o en mano & 77,3 \\
\hline Puesto fijo & 59,1 \\
\hline Cacería de zorros & 42,4 \\
\hline Gancho de caza menor & 32,3 \\
\hline Perros en Madriguera & 27,9 \\
\hline Suelta para su abatimiento inmediato & 25,3 \\
\hline Ojeo & 17,8 \\
\hline Perdiz con reclamo & 12,6 \\
\hline Caza con galgos & 8,6 \\
\hline Cetrería & 3,0 \\
\hline \multicolumn{2}{|l|}{ Modalidades de caza mayor } \\
\hline Montería & 77,7 \\
\hline Aguardo o espera & 55,8 \\
\hline Batida & 49,1 \\
\hline Gancho & 36,4 \\
\hline Rececho & 29,7 \\
\hline Arco & 1,1 \\
\hline \multicolumn{2}{|c|}{ ¿Con qué frecuencia caza en cotos sociales? } \\
\hline Nunca & 4,5 \\
\hline En alguna ocasión & 10,8 \\
\hline Habitualmente & 37,9 \\
\hline Siempre & 45,7 \\
\hline NS/NC & 0,4 \\
\hline \multicolumn{2}{|c|}{ ¿Con qué frecuencia caza en cotos privados? } \\
\hline Nunca & 11,5 \\
\hline En alguna ocasión & 35,3 \\
\hline Habitualmente & 37,9 \\
\hline Siempre & 14,5 \\
\hline $\mathrm{NS} / \mathrm{NC}$ & 0,8 \\
\hline \multicolumn{2}{|c|}{ Si no existieran los cotos sociales, ¿podría practicar la caza con la misma frecuencia? } \\
\hline Sí & 27,5 \\
\hline No & 72,1 \\
\hline $\mathrm{NS} / \mathrm{NC}$ & 0,4 \\
\hline \multicolumn{2}{|l|}{ ¿Está federado? } \\
\hline Sí & 81,8 \\
\hline No & 17,5 \\
\hline NS/NC & 0,7 \\
\hline
\end{tabular}

Fuente: Datos procedentes de la encuesta. Elaboración propia.

\subsection{Gastos realizados por el cazador social durante la temporada de caza 2018/2019}

Los cazadores realizan multitud de gastos durante la temporada de caza en diferentes sectores (hostelería, administración pública, armerías, etc.), siendo el promedio global del gasto realizado por cazador 
durante esta temporada de caza de $861 €$. Dentro de ellos, el generado por los viajes cinegéticos es el de mayor envergadura. No es de extrañar este dato debido a la notable movilidad que caracteriza al cazador extremeño (Martín, et al., 2020) Concretamente el promedio de gasto referente a esta actividad asciende a $840 €$ por cazador durante la temporada de caza 2018/2019 según los resultados obtenidos en esta investigación. Estos gastos se desglosan en diferentes servicios: alojamiento en el destino cinegético, transporte, gastronomía, así como las diferentes actividades que realiza durante el viaje.

Por otro lado, el cazador también invierte bastante dinero en la adquisición de equipamiento, fundamentalmente, en la compra de ropa, munición y armas, entre otros. Este promedio de gasto se sitúa en $716 €$ de media por cazador según lo descrito por los encuestados.

Por último, el capítulo de gasto más modesto se corresponde con los pagos referentes a seguros, tasas de licencias, cuotas de sociedades, compra de acciones cinegéticas o el alquiler de cotos. Esta cifra se sitúa en torno a $640 €$ por cazador tal y como afirman los encuestados.

Estas cifras confirman el papel económico que juega el cazador social en Extremadura mediante el efecto multiplicador de gasto en diferentes sectores. El informe de la Federación Extremeña de Caza (Gallardo et al., 2019) estima la importancia económica de la actividad cinegética a escala regional, de manera que el total de ingresos generados, exclusivamente, por la expedición de licencias de caza para la temporada 2016/17 fue de 676.874,94€, a los que habría que añadir el resto de gastos destinados a la adquisición de equipamientos, seguros o a los derivados de los movimientos del cazador por la región.

\subsection{Influencia del nivel de renta en el perfil del cazador social}

La caza social es, por tanto, una parte esencial del mundo cinegético extremeño destacando el papel que realizan las Sociedades Locales de Cazadores. Estas organizaciones cinegéticas se muestran como baluartes defensivos del cazador más modesto, al permitirle el acceso a un importante número de terrenos cinegéticos gestionados por estas sociedades (Alvarado, 1991a, 1991b; López, 1991; Mulero, 1991a; Martín, et al., 2019a). Por ello, resulta interesante determinar el nivel de ingresos de este tipo de cazador, así como conocer si esta renta mensual incide de alguna manera en otras características del perfil del cazador social.

Para determinar la relación de los ingresos mensuales del cazador social residente en Extremadura con otras variables de estudio se han empleado los coeficientes de correlación R de Pearson y Tau B de Kendall, al considerarse los más adecuados ante las características de las variables de estudio (Morales y Rodríguez, 2016). Entre los resultados obtenidos tras la aplicación de ambos coeficientes puede apreciarse la relación existente entre la pertenencia a un grupo de edad y el nivel de ingresos que este cazador presenta. De esta manera, se observa una correlación positiva incrementándose el nivel de ingresos mensuales a medida que la edad del cazador aumenta. Por otro lado, la formación parece determinar el nivel de ingresos mensuales que el cazador percibe presentando una correlación positiva ambas variables. Según los datos obtenidos de la muestra de estudio al poseer una formación superior los ingresos mensuales parecen incrementarse, situación que puede estar vinculada al hecho de que estar en disposición de un mayor nivel formativo da acceso a escalas de trabajo donde los ingresos mensuales son superiores (Tabla 8). Al mismo tiempo, percibir una mayor renta mensual permite al cazador social incrementar la escala del viaje, así a medida que el nivel de ingresos incrementa el cazador se desplaza a lugares situados a una mayor distancia de su lugar de residencia. Las razones de estos viajes vendrían dadas por la diversidad y abundancia de especies en otros cotos.

Recapitulando, en Extremadura se reconoce la existencia de dos modelos de caza: la social y la económica (Junta de Extremadura, Ley 14/2010). La caza social tiene lugar en terrenos bajo gestión pública, así como en acotados cuya gestión es realizada por sociedades locales de cazadores denominados cotos sociales. Por otro lado, la caza económica se lleva a cabo en acotados privados, donde las jornadas venatorias tienen costes económicos de diferente cuantía. Esta situación determina los resultados obtenidos en esta investigación corroborando como la frecuencia en la que el cazador social caza en coto social se reduce a medida que se incrementan sus ingresos mensuales. Al mismo tiempo, este incremento en la renta conduce a que la frecuencia en la que caza en cotos privados aumente. 
Tabla 8. Coeficientes de Correlación

\begin{tabular}{|c|c|c|c|c|c|c|c|}
\hline \multirow{2}{*}{$\frac{\text { Variables }}{\text { Edad }}$} & \multicolumn{5}{|c|}{ \% Ingresos mensuales } & \multicolumn{2}{|c|}{ Coeficientes de correlación } \\
\hline & $<1000$ & $1001-1500$ & $1501-2000$ & $2001-2500$ & $>2500$ & $\mathrm{R}$ de Pearson & Tau_b de Kendall \\
\hline Menor de 18 años & 100,0 & 0,0 & 0,0 & 0,0 & 0,0 & \multirow{6}{*}{$0,208 * *$} & \multirow{6}{*}{$0,183 * *$} \\
\hline Entre 18 y 25 años & 48,5 & 45,5 & 0,0 & 0,0 & 6,0 & & \\
\hline Entre 26 y 40 años & 18,7 & 54,7 & 16,0 & 2,6 & 8,0 & & \\
\hline Entre 41 y 55 años & 22,1 & 46,5 & 16,3 & 8,1 & 7,0 & & \\
\hline Entre 56 y 65 años & 20,0 & 35,6 & 20,0 & 8,8 & 15,6 & & \\
\hline Más de 65 años & 31,3 & 18,7 & 0,0 & 18,7 & 31,3 & & \\
\hline \multicolumn{8}{|l|}{ Nivel de estudios } \\
\hline Básico & 36,5 & 47,6 & 6,3 & 2,4 & 7,2 & \multirow[b]{3}{*}{$0,251 * *$} & \multirow[b]{3}{*}{$0,256^{* *}$} \\
\hline Medio & 17,8 & 48,0 & 17,8 & 8,2 & 8,2 & & \\
\hline Superior & 15,2 & 33,9 & 23,7 & 11,9 & 10,2 & & \\
\hline \multicolumn{8}{|l|}{ Lugares en los que caza } \\
\hline Solo en su municipio & 42,5 & 42,5 & 7,5 & 2,5 & 5,0 & \multirow{4}{*}{$0,321^{* *}$} & \multirow{4}{*}{$0,280 * *$} \\
\hline $\begin{array}{l}\text { En su municipio y en otros } \\
\text { de su comunidad autónoma }\end{array}$ & 32,3 & 51,6 & 11,8 & 3,2 & 1,1 & & \\
\hline $\begin{array}{l}\text { En su comunidad autónoma } \\
\text { y en otras diferentes }\end{array}$ & 19,0 & 42,0 & 17,0 & 8,0 & 14,0 & & \\
\hline $\begin{array}{l}\text { En España y en otros países } \\
\text { del extranjero }\end{array}$ & 9,0 & 36,4 & 18,2 & 18,2 & 18,2 & & \\
\hline \multicolumn{8}{|l|}{$\begin{array}{l}\text { Frecuencia con la que } \\
\text { caza en cotos sociales }\end{array}$} \\
\hline Nunca & 16,7 & 41,7 & 0,0 & 25,0 & 16,6 & \multirow{4}{*}{$-0,284 * *$} & \multirow{4}{*}{$-0,235 * *$} \\
\hline En alguna ocasión & 13,8 & 27,5 & 24,1 & 13,9 & 20,7 & & \\
\hline Habitualmente & 22,1 & 48,4 & 14,7 & 6,3 & 8,4 & & \\
\hline Siempre & 34,5 & 46,5 & 12,1 & 2,6 & 4,3 & & \\
\hline \multicolumn{8}{|l|}{$\begin{array}{l}\text { Frecuencia con la que } \\
\text { caza en cotos privados }\end{array}$} \\
\hline Nunca & 48,2 & 41,4 & 3,5 & 3,5 & 3,4 & \multirow{4}{*}{$0,301 * *$} & \multirow{4}{*}{$0,246 * *$} \\
\hline En alguna ocasión & 31,5 & 47,2 & 15,8 & 3,3 & 2,2 & & \\
\hline Habitualmente & 21,6 & 43,3 & 17,5 & 8,2 & 9,4 & & \\
\hline Siempre & 13,2 & 44,7 & 7,9 & 10,5 & 23,7 & & \\
\hline
\end{tabular}

Fuente: datos procedentes de encuestas. Elaboración propia.

\section{Discusión}

El modelo de caza social tiene una gran representatividad en Extremadura tanto en términos superficiales, así como con el protagonismo de las Sociedades Locales de Cazadores como gestoras de este tipo de terrenos, aglomerando a una buena parte de los cazadores extremeños. La mayor proliferación de este tipo de sociedades tuvo lugar en la década de los ochenta en Extremadura (Martín, et al., 2019a) tras la asunción de competencias en materia de caza por el gobierno autonómico. El calado que este modelo cinegético alcanza en el siglo XX-XXI llevó a que en la primera Ley de caza en Extremadura (1991) ya se reconocieran dos modelos cinegéticos: el social y el económico. A pesar del reconocido protagonismo de 
la caza social en esta comunidad autónoma, esta investigación pone de manifiesto el escaso interés científico que ha tenido en este territorio, donde tan sólo un estudio se ha decantado por su análisis de forma monográfica (Martín, et al., 2019a). A nivel nacional se reproduce este mismo escenario, aunque existe un mayor número de trabajos que han abordado esta cuestión (Ortuño, 1970; Fernández, 1985; Mulero, 1991a; Gutiérrez, 2013; Barceló et al., 2015 y 2016). Sin embargo, estos parecen escasos si se comparan con aquellos dedicados a la llamada caza comercial de la que se deriva un mayor impacto económico (Martínez, 1984; Cecilia y Martínez, 1989; Mulero, 1991b; Danzberger, 2009; Coca, Álvarez y Hernández, 2007; Casado, Coca, Escamillas y Prado, 2015; Andueza et al., 2016; Barceló, Campaner y Rengifo, 2017; Andueza et al., 2018).

Por otro lado, los trabajos de índole científico a escala nacional determinan la notable masculinización del sector (Fernández, 1985; Barceló et al., 2016), situación que también se aprecia en esta comunidad autónoma donde la mayor parte de cazadores son hombres frente a un escaso número de mujeres. Al mismo tiempo, el envejecimiento es otra de las características del sector, donde existe un reducido número de cazadores menores de 26 años. En Extremadura, uno de los retos asumidos por el sector cinegético a corto y medio plazo según lo descrito por Rengifo en el año 2012 (Rengifo, 2012) era garantizar el relevo generacional en esta actividad. Sin embargo, los resultados obtenidos en esta investigación ocho años después acreditan que este reto continúa vigente, predominando el perfil del cazador maduro, frente a una reducida presencia de jóvenes. Martín, et al. (2019a) muestran como posible solución a este problema la paulatina incorporación de la mujer.

La literatura científica sobre la actividad cinegética, tradicionalmente, ha definido a las Sociedades Locales de Cazadores como baluartes defensivos del cazador modesto frente aquel que presenta un mayor poder adquisitivo (López, 1991; Alvarado, 1991a; Mulero, 1991a). Los resultados obtenidos en esta investigación acreditan estos datos, donde la mayor parte de los cazadores sociales presentan unos ingresos mensuales medios (1.001-1.500€) y bajos (menos de 1.000€). De esta forma, la práctica venatoria del cazador social se realiza con mayor frecuencia en acotados de tipo social que en cotos privados, ante las mayores connotaciones económicas que implica cazar en estos últimos terrenos cinegéticos. Sin embargo, una parte representativa de la muestra de este estudio manifiesta disponer de ingresos superiores a $1.500 €$ $(27,8 \%)$ que pueden identificarse con un perfil económico más elevado practicando la caza en cotos privados con una mayor frecuencia.

Además de los cotos sociales, el cazador en Extremadura dispone de una serie de terrenos cinegéticos que responden a una finalidad social, en un sentido no estricto del término. Se trata de los terrenos gestionados por la Administración Pública, cuyos permisos para cazar se adjudican tras un sorteo público cada temporada de caza, siendo el grupo de cazadores locales los que resultan más beneficiados. Según lo descrito por el gobierno autonómico se reservan una serie de permisos a cazadores locales, autonómicos y nacionales (http://extremambiente.juntaex.es/index.php?option=com_content\&view=article\&i-

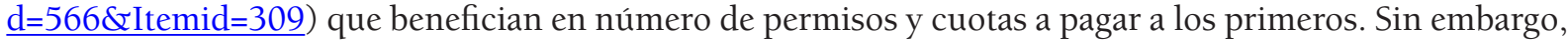
entre los requisitos para el acceso a este tipo de terrenos no se determina un nivel de ingresos económicos.

\section{Conclusiones}

Entre las principales conclusiones derivadas de esta investigación pueden citarse las siguientes como las más importantes:

- El perfil sociodemográfico del cazador social se identifica con una figura predominantemente masculina y madura, donde destaca el grupo etario entre 26 y 55 años. Al mismo tiempo, se ha observado una escasa presencia de la mujer cazadora, así como de jóvenes menores de 26 años.

- Además, este cazador posee un bajo nivel formativo $(49,1 \%)$ condicionando la renta mensual percibida. De esta forma, la mayor parte de la muestra de este estudio afirma disponer de ingresos mensuales que se sitúan entre los 1.001 y $1.500 €$. Por otro lado, en lo referente a la situación laboral predomina el grupo de trabajadores por cuenta ajena $(42,8 \%)$ frente a otras opciones como autónomos, funcionarios, jubilados o estudiantes.

- La actividad cinegética presenta una fuerte tradición entre las familias de los cazadores sociales $(80,7 \%)$ produciéndose la incorporación de estos al mundo venatorio con edades muy tempranas. Así, el 80,7\% de los encuestados afirma haber comenzado a cazar con menos de 18 años. Al mismo tiempo, existe un profundo interés por inculcar esta actividad de padres a hijos $(62,8 \%)$. 
- Los viajes de caza están muy presentes entre los cazadores sociales manifestando el 84,4\% de los encuestados realizar diferentes movimientos con motivo de la práctica venatoria. Dentro del grupo de cazadores sociales se distinguen dos tipos de viajeros en función de la duración del viaje: turistas y excursionistas. Estos viajes cinegéticos se producen, fundamentalmente a tres escalas: autonómica, nacional e internacional. Entre ellos destaca la incidencia de los viajes autonómicos y nacionales. A pesar de ello, debido a las cortas distancias de recorrido que tienen estos viajes la incidencia de la pernoctación es muy escasa entre los encuestados (52,0\%).

- Las principales modalidades de caza llevadas a cabo por el cazador social extremeño son la práctica al salto o en mano, en el caso de la caza menor, y la montería, en la mayor.

- La práctica venatoria se realiza con mayor frecuencia en cotos sociales que en privados. De esta forma, el $72,1 \%$ de los encuestados afirma que no podría cazar con la misma frecuencia si no existiera este tipo de acotado.

- La Federación Extremeña de Caza presenta un notable protagonismo entre los cazadores sociales manifestando el $81,8 \%$ de la muestra de estudio pertenecer a esta organización cinegética.

- El cazador social realizó un notable gasto durante la temporada de caza 2018/2019, situándose el gasto medio por cazador en $861 €$. Entre los diferentes gastos que realiza se encuentra el destinado a la adquisición de equipamientos, desplazamientos (el más relevante) y el destinado al pago de seguros y licencias.

\section{Financiación}

Esta publicación se encuadra dentro de las investigaciones llevadas a cabo durante la ejecución del proyecto "Diseño y elaboración de productos estratégicos diferenciados para la potenciación del turismo rural en Extremadura. De la detección de problemas a la propuesta de soluciones basadas en criterios geoestadísticos", cuya clave es IB 16040, y se encuentra financiado por la Consejería de Economía e Infraestructuras de la Junta de Extremadura y por el Fondo Europeo de Desarrollo Regional (FEDER).

\section{Referencias}

Alvarado, E. (1983). Los espacios rurales y el ocio. Los cotos de caza (Cáceres 1973-1983). En VIII Coloquio de Geógrafos Españoles (pp. 149-155). Bacelona: AGE.

Alvarado, E. (1991a). La actividad cinegética en Extremadura. Agricultura y Sociedad, 58, 215-240.

Alvarado, E. (1991b). Socioeconomía de la caza. El ejemplo Extremeño. En E. Alvarado, J. F. Beltrán y J. Carranza (Coords.), Manual de ordenación y gestión cinegética (pp. 21-51). Badajoz: IFEBA.

Alvarado, E., Carranza, J. \& Beltrán, J. (1991). Manual de Ordenación y Gestión cinegética. Badajoz: IFEBA.

Álvarez, A., \& Remedios, N. (2017). Gestión de la cabra montés en la Reserva de Caza La Sierra. (Spanish). Montes, 73-76. Recuperado de http://7cfe.congresoforestal.es/content/gestion-de-la-cabra-montes-enla-reserva-de-caza-la-sierra

Álvarez, P., Coca, J., \& Hernández, J. (2007). El turismo cinegético como recurso de primer orden para el desarrollo sostenible de Extremadura. Modalidades: montería y ojeo de perdiz roja. En R. Hernández y V. Postigo (Eds.), Competencias sin fronteras. La empresa familiar (pp. 453-470). Trujillo: Ediciones La Coria.

Andueza, A., Lambarri, M., Urda, V., Prieto, I., Villanueva, L., \& Sánchez-García, C. (2016). Evaluación del Impacto Económico y Social de la Caza en España. Informe de resultados 2.016. Ciudad Real: Fundación Artemisan.

Andueza, A., Lambarri, M., Urda, V., Prieto, I., Villanueva, L., \& Sánchez-García, C. (2018). Evaluación del Impacto Económico y Social de la Caza en España. Ciudad Real: Fundación Artemisan. Recuperado de https://www.fundacionartemisan.com/wp-content/uploads/2018/02/Informe-Caza-Castilla-LaMancha-Deloitte-Artemisan.pdf

Aparicio, M. A., \& Vargas, J. D. (1991). La caza en Extremadura. Seminario Internacional sobre economía y conservación de sistemas agrosilvopastorales mediterráneos de dehesas y de montados. Badajoz.

Aparicio, M.A., \& Vargas, J.D. (2002). Aspectos Económicos de la caza en Extremadura. Rumiantes, 24-48. 
Barceló, A., Binimelis, J., \& Grimalt, M. (2016). Caracterización del perfil social y territorial del cazador mallorquín. Treinta años de Política Agraria Común en España: Agricultura y multifuncionalidad en el contexto de la nueva ruralidad, 496-511. Recuperado de https://dialnet.unirioja.es/servlet/ $\underline{\text { libro? codigo }=660685}$

Barceló, A., Campaner, B., \& Rengifo, J.I. (2017). La caza de la cabra salvaje mallorquina en el contexto del turismo cinegético/The hunting of the mallorcan wild goat in the context of cynegetic tourism. Ería, 2(2), 233-252. https://doi.org/10.17811/er.2.2017.233-252

Barceló, A., Grimalt, M., \& Binimelis, S. (2015). Implicaciones territoriales, sociales y ambientales de las sociedades de cazadores locales en Mallorca. Análisis espacial y representación geográfica: innovación y aplicación, 1.543-1.552. Recuperado de http://congresoage.unizar.es/eBook/trabajos/163_Barcelo\%20 Adrover.pdf

Barceló, A., Binimelis, S., \& Grimalt, M. (2017). Análisis bibliométrico de los estudios geográficos de la caza en España (1978-2015). Boletín de la Asociación de Geógrafos Españoles, (74). https://doi. org/10.21138/bage. 2456

Bardají, M. (1987). La caza en las dehesas extremeñas. La caza en Extremadura: comunicaciones con motivo del I Congreso Internacional de la caza En Extremadura, (pp. 225-231). Cáceres.

Barlés, M. J. (2012). Perfil del turista de festivales: el caso del Festival Internacional de las Culturas Pirineos Sur.Cuadernos de Turismo, 30, 63-90.

Barrientos, G. (1991). La provincia de Extremadura al final del siglo XVIII. (Descripciones recogidas por Tomás López). Mérida, Asamblea de Extremadura.

Bielsa, J. (1987). Caza mayor como alternativa de desarrollo en zonas deprimidas de Extremadura. La caza en Extremadura: comunicaciones con motivo del I Congreso Internacional de la caza En Extremadura.

Calvo, S. (1988). Extremadura. Tradición de la caza. Madrid: Diputación Provincial de Cáceres.

Campos, FJ. (2003). Las relaciones topográficas de Felipe II: índice, fuentes y bibliografía. Anuario Jurídico y económico escurialense, XXXVI, 440-574

Casado, P., Coca, J., Escamillas, S., \& Prado, C. (2015). El turismo cinegético: Una oportunidad sostenible para el turismo rural. Tourism and Hospitality International Journal, 89-104. Recuperado de http://ci.isce.pt/static/uploads/Paola\%20Plaza\%20Casado,\%20Jos\%20Luis\%20Coca\%20Prez,\%20 Sandra\%20Escamilla\%20Solano,\%20Camilo\%20Prado\%20Romn.pdf

Castilla, M. (2000). La Ley extremeña de caza y su matizada constitucionalidad. Derechos Civiles en España, 4.599-4.638.

Cecilia, J., \& Martínez, E. (1989). La caza, un negocio muy mayor. Expansión, 1.013, 40-41.

Coca, J.L. (2015). Hunting tourism in Extremadura: Spanish Monteria. Tourism and Hospitality International Journal, (4,1), 12-23.

Coca, J.L., Álvarez, P., \& Hernández, J.M. (2007). Turismo cinegético: un recurso económico de primer orden para el desarrollo sostenible de muchos territorios. En VII Encuentro Hispano-luso de economia empresarial (pp. 182-187). Algarve.

Coca, J.L., Plaza, P., Del Río, M.C., \& Álvarez, J. (2015). La diversificación económica sostenible del medio rural a través del turismo cinegético. Cultur: Revista de cultura e turismo, 9(3), 44-63. Recuperado de http://periodicos.uesc.br/index.php/cultur/article/view/936

Consejería de Medio Ambiente y Rural, Políticas Agrarias (1991). Orden de 29 de mayo de 1991 por la que se establecen los períodos hábiles de caza para la temporada de caza 1991/92.

Consejería de Medio Ambiente y Rural, Políticas Agrarias (2012). Decreto 91/2012, de 25 de mayo, por el que se aprueba el Reglamento por el que se regula la gestión cinegética y el ejercicio de la caza. Junta de Extremadura, DOE, 105.

Consejería de Medio Ambiente y Rural, Políticas Agrarias (2017). ORDEN de 21 de agosto de 2017 General de Vedas de Caza para la temporada 2017/2018, de la Comunidad Autónoma de Extremadura. DOE, 163.

Consejería de Medio Ambiente y Rural, Políticas Agrarias (2018). ORDEN de 21 de agosto de 2017 General de Vedas de Caza para la en Extremadura. Documento Oficial de Extremadura(163).

Covarsí,A. (1998). Obras Completas. Madrid: Editorial Casariego. 
Danzberger, J. (2009). La caza: un elemento esencial en el desarrollo rural. Mediterráneo Económico: El nuevo sistema agroalimentario en una crisis global, 15, 183-203. Recuperado de https://dialnet.unirioja. es/servlet/articulo? codigo $=2981819$

EUROCAZA (2001). I Jornadas Europeas sobre caza, empresa y desarrollo. Azuaga: Centro de desarrollo rural Campiña Sur.

EUROCAZA (2003). La caza como actividad impulsora de desarrollo sostenible. Azuaga: Centro de desarrollo rural Campiña Sur.

EUROCAZA (2004). La caza como recurso económico y turístico. Azuaga: Centro de desarrollo rural Campiña Sur.

Fernández, F. (1985). Las sociedades de cazadores en Asturias. Los cotos de caza privados. Oviedo: Consejería de Agricultura del Principado de Asturias.

Fernández, T. (1992). Cáceres: el sector de la caza. Cáceres: Cámara Oficial de Comercio e Industria.

Folgado, J., \& Hernández, J. (2014). El perfil del turista de eventos culturales:análisis exploratorio. En Cultura, desarrollo y nuevas tecnologías: VII Jornadas de investigación (pp. 57-74). Recuperado de https://idus.us.es/handle/11441/53047

Fuentes, A., \& Sánchez, I. (1992). La nueva ordenación de la caza en Extremadura. En Viola, J.J., La agricultura y ganadería extremeñas en 1.991 (pp. 213-221). Cáceres: Diputación Provincial de Cáceres.

Fradejas, J.M. (2017) Los libros de caza medievales y su interés para la historia natural. Arbor, 193, (786), 1-10. https://doi.org/10.3989/arbor.2017.786n4002

Gallardo, M., Gallardo, J., Gómez, M., \& Rodero García, S. (2016). Situación de la caza en Extremadura. Badajoz: Federación Extremeña de Caza.

Gallardo, M., Rodero, S., Gómez, M., Gallardo, J.M., Arroyo, V., \& Durán, J.A. (2018). Situacióm de la caza en Extremadura. Informe Anual Temporada (2016/2017).

Gamonales, J., Guzmán, L., \& Muñoz, J. (2016). Condición física y hábitos de prácticas físico deportiva de los cazadores extremeños. E-balonmano.com Journal of Sports Science, 12(3), 207. Recuperado de http:// dehesa.unex.es/bitstream/handle/10662/6786/1885-7019_12_3_207.pdf?sequence=1\&isAllowed=y

García, M. (1987). La Tórtola en Extremadura. La Caza en Extremadura. I: Congreso Internacional de la Caza en Extremadura. Cáceres: Diputación provincial de Cáceres.

Gutiérrez, J. (2013). El potencial de las sociedades de cazadores como herramienta de conservación en España. Ecosistemas, 104-106. https://doi.org/10.7818/ECOS.2013.22-2.15

Guzmán, L., \& Gamonales, J. (2012). Valoración de la condición física y estilos de vida relacionados con el consumo de tabaco y alcohol de los cazadores extremeños (Trabajo de Máster). Universidad de Extremadura. Extremadura.

Hidalgo, S.J., \& Rocha, G. (2001). Valoración de la presión cinegética sobre la Tórtola Común en Extremadura. Cuadernos de Ciencias Naturales, (16), 157-171. Recuperado de https://core.ac.uk/ download/pdf/11502617.pdf

Hidalgo, S.J., \& Rocha, G. (2005). Revisión del status de la tórtola común en Extremadura, Implicaciones en su conservación. En J. López Caballero (Ed.), Conservación de la Naturaleza en Extremadura (pp. 427-433). Mérida: Consejería de Agricultura y Medio Ambiente, Junta de Extremadura.

Instituto Nacional para la Conservación de la Naturaleza. (1970-1980). Anuario de Estadística Agraria.

Junta de Extremadura. Ley 8/1990, de 21 de diciembre de Caza en Extremadura.

Junta de Extremadura. Ley 14/2010, de 9 de diciembre, de caza de Extremadura. DOE, número 239. Recuperado de http://doe.gobex.es/pdfs/doe/2010/2390o/10010016.pdf.

Junta de Extremadura. Ley 12/2014, de 19 de diciembre de modificación de la Ley 14/2010, de 9 de diciembre, de caza de Extremadura, y de la Ley 18/2.001, de 14 de diciembre, sobre tasas y precios públicos de la Comunidad Autónoma de Extremadura.

Junta de Extremadura (2019). Datos propios. Extremambiente. Recuperado de http://extremambiente. juntaex.es/index.php?option=com_content\&view=article\&id=1288\&Itemid=459

Junta de Extremadura. Ley 9/2019, de 5 de abril, por la que se modifican la Ley 14/2010, de 9 dediciembre, de caza de Extremadura, y la Ley 18/2001, de 14 de diciembre, sobre tasas y precios públicos de la 
Comunidad Autónoma de Extremadura. DOE, número 70. Recuperado de http://doe.gobex.es/pdfs/ doe/2019/700o/19010009.pdf.

Junta de Extremadura. Decreto 34/2016 de 15 de marzo, por el que se aprueba el Reglamento por el que se regula el ejercicio de la caza, la planificación y ordenación cinegética.

Lázaro, I. (2004). La caza en Extremadura. Foresta, 144-151.

Leco, F. (1997). Potencialidades turísticas de las dehesas extremeñas. La actividad cinegética. En M. Valenzuela (Coord.), Los turismos de interior: el retorno a la tradición viajera (pp. 161-167). Madrid: Ediciones de la Universidad autónoma de Madrid.

Ledesma, M. (1989). La caza en las cartas de población y fueros de la extremadura aragonesa. Aragón en la Edad Media, 427-440.

López, A. (1981). El desarrollo reciente de la caza en España. Supervivencia de la Montaña, Actas del Coloquio Hispano-Francés sobre las Áreas de Montaña (pp. 271-297). Madrid: Servicio de Publicaciones Agrarias. Ministerio de Agricultura.

López, A. (1991). Algunos aspectos de la evolución de la caza en España. Agricultura y Sociedad, 58, 13-52. Recuperado de https://helvia.uco.es/bitstream/handle/10396/5594/a058_01.pdf?sequence=1

López, A. (1993). Importancia de la geografía cinegética en el contexto de la geografía agraria española. En A. Gil Olcina, \& A. Morales Gil (Coords.), Medio siglos de cambios agrarios en España (pp. 191216). Alicante: Instituto de cultura "Juan Gil-Albert".

Madoz, P. (1953-1955). Diccionario histórico-geográfico de Extremadura. Cáceres: Publicaciones del Departamento de Seminarios de la Jefatura Provincial del Movimiento. 4 tomos.

Martín, L.M., Rengifo, J.I., \& Sánchez, J.M. (2019a). El modelo de caza social: evolución y caracterización en Extremadura. Boletín de la Asociación de Geógrafos Españoles, 82, 1-37. https://doi.org/10.21138/ bage. 2793

Martín, L.M., Rengifo, J.I., \& Sánchez, J.M. (2019b). El turista cinegético. Una aproximación a su perfil en la comunidad autónoma de Extremadura. Investigaciones Turísticas de la Universidad de Alicante, 18, 193-219. http://dx.doi.org/10.14198/INTURI2019.18.09

Martín, L.M., Rengifo, J.I., \& Sánchez, J.M. (2020). Hunting in Extremadura-Profiles of the Hunter on the Basis of His Movements. Resources, 9, 4(46). https://doi.org/10.3390/resources9040046

Martínez, E. (1984). La caza como aprovechamiento agrario. Un ejemplo de explotación silvo-agropecuario-cinegética: La Almoraima. Caza y Pesca, 499, 442-444.

Martínez, E. (2009). Visiones territoriales del boom cinegético español, 1970-1989. Boletín de la Asociación de Geógrafos Españoles, 325-351.

Mateos, J. (1979). Origen y dignidad de la caza. Madrid: Ediciones Velázques.

Montero, S. (2019). Encuentros de vida y muerte. Antropología transespecie y mundos ampliados entre cazadores y animales en el suroeste extremeño (Tesis doctoral). Sevilla: Universidad Pablo Olavide.

Morales, P., \& Rodríguez, L. (2016). Aplicación de los coeficientes correlación de Kendall y Spearman. Barquisimeto. Venezuela: Universidad Centroccidental Lisandro Alvarado (UCLA).

Morgado, P. (1998). Situación e impacto sobre el medio de las poblaciones de caza mayor en el Parque Natural de Monfragüe. Cáceres: Junta de Extremadura.

Mulero, A. (1991a). La organización local de la caza en España. Agricultura y Sociedad, 58, 187-213. Recuperado de https://helvia.uco.es/bitstream/handle/10396/5619/a058_07.pdf? sequence=1

Mulero, A. (1991b). Turismo y caza en España. Estado de la cuestión. Agricultura y Sociedad, 58, 147-171. Recuperado de https://helvia.uco.es/bitstream/handle/10396/5618/a058_05.pdf? sequence=1

Nogueras, J., Caridad, J., \& Gálvez, J. (2017). El perfil del turista cinegético: un estudio de caso para Córdoba. International Journal of Scientific managment and tourism, 3, 187-203. Recuperado de https:// dialnet.unirioja.es/servlet/articulo? codigo $=6182529$

Ortuño, F. (1970). Aspectos sociales de la caza. Revista de estudios Agrosociales (70), 7-23. Recuperado de https://dialnet.unirioja.es/servlet/articulo? codigo $=2200791$

Rengifo, J.I. (2012). Evaluación de la actividad cinegéticas en Extremadura. Albores del siglo XXI: Retos a corto y medio plazo. Estudios Geográficos, 272, 189-214. https://doi.org/10.3989/estgeogr.201207 
Rocha, G., \& Hidalgo, S.J. (2000). Análisis de la caza menor en Extremadura. EUROCAZA.

Rodríguez, M., \& Barrientos, G. (1993, 1994, 1995, 1996) Interrogatorio de la Real Audiencia: Extremadura a finales de los tiempos modernos. Partido de Plasencia, Trujillo, Poblaciones disgregadas, Cáceres, La Serena, Badajoz, Coria, Llerena, Mérida, Alcántara. Asamblea de Extremadura

Rubio, J., \& Pérez, A. (1998). La actividad cinegética en Extremadura: caza y desarrollo rural (Trabajo fin de grado). Cáceres: Universidad de Extremadura.

Serrano, B., \& Martínez, E. (2005). Caza y naturaleza en Monfragüe. Cáceres: Centrales Nucleares Almaraz-Trillo.

Terrón, A. (1981). Discursos leídos ante la Real Academia de Extremadura. Badajoz: Institución Cultural Pedro de Valencia.

Terrón, A. (2003). Los recursos cinegéticos de Extremadura. Cáceres: Universidad de Extremadura.

Terrón, M. (1971). El solar de los aftásidas. Badajoz: Centro de Estudios Extremeños. Instituto Pedro de Valencia.

Terrón, M. (1975). De la panorámica de la caza en Extremadura. En C. Orellana (Ed.), Los libros de la caza española, (pp. 473-520). Madrid.

Terrón, M. (1987). De la Extremadura agreste: Notas para un estudio de la evolución histórica de la fauna de caza mayor. En La caza en Extremadura: comunicaciones con motivo del I Congreso Internacional de la caza En Extremadura (pp. 31-71). Cáceres: Diputación Provincial de Cáceres.

Terrón, M. (1992). El conocimiento animalístico de la caza mayor en los clásicos de la montería hispana. En Siglos XVI y XVII / Manuel Terrón Albarrán (pp. 371-501). Trujillo, Real Academia de Extremadura de las letras y las Artes.

Terrón, M. (2002). La Montería de Alfonso XI, 1311-1350, Técnica Venatoria Tipología de los Montes. Separata en tirada aparte de 110 ejemplares del volumen V de las Memorias de la Real Academia de Extremadura de la Letras y las Artes: Trujillo.

Varona, J. (1976). Instrucción de cazadores. Badajoz: Institución Pedro de Valencia de la Excma. Diputación Provincial.

Viola, J.J. (Dir.) (1987). La caza en Extremadura: comunicaciones con motivo del I Congreso Internacional de la caza En Extremadura. Cáceres.

Zapata, L. (1979). Libro de Cetrería. Badajoz: Institución Pedro de Valencia de la Excma. Diputación Provincial. 